\title{
A spatial system dynamic model for regional desertification simulation - A case study of Ordos, China
}

\author{
Duanyang $\mathrm{Xu}^{\mathrm{a}}$, Alin Song ${ }^{\mathrm{b}}$, Hefeng Tong ${ }^{\mathrm{c}}$, Hongyan Ren ${ }^{\mathrm{a}}$, Yunfeng $\mathrm{Hu}{ }^{\mathrm{a}}$, \\ Quanqin Shao ${ }^{\text {a, * }}$ \\ a Institute of Geographic Sciences and Natural Resources Research, CAS, Beijing 100101, PR China \\ ${ }^{\mathrm{b}}$ Institute of Agricultural Resources and Regional Planning, CAAS, Beijing 100081, PR China \\ ${ }^{\mathrm{c}}$ Institute of Scientific and Technical Information of China, Beijing 100038, PR China
}

\section{A R T I C L E I N F O}

\section{Article history:}

Received 26 August 2015

Received in revised form 13 April 2016

Accepted 19 May 2016

Available online 2 June 2016

\section{Keywords:}

Desertification

Simulation

Model

Spatial system dynamic

China

\begin{abstract}
A B S T R A C T
A spatial system dynamic (SSD) model for simulating desertification was developed by integrating climate, soil water, population, economy, pasturage, and land use. Net Primary Production (NPP) was selected as an intermediate variable to measure the impacts of driving forces and desertification grades. Ordos in China was selected to test the model. Ten scenarios were designed to simulate desertification dynamics in Ordos from 2011 to 2030. The results showed that the SSD model was reliable, and the overall accuracy of desertification degree was approximately $83 \%$. Climate factors had relatively higher sensitivities than other parameters. Although humid climate and sustainable development strategy would reduce desertified land area and desertification degree before 2025, the rapid increase in pasturage pressure would offset this trend. Arid climate and unsustainable development strategy would accelerate desertification expansion. For local government, it is necessary to persist in the present desertification prevention policy and completely banned grazing after 2025 .
\end{abstract}

(c) 2016 Elsevier Ltd. All rights reserved.

\section{Introduction}

Desertification is defined as land degradation in arid, semi-arid, and dry sub-humid areas resulting from various factors including climatic variations and human activities (UNCCD, 1994). The interaction of driving forces at different spatio-temporal scales leads to a highly complex desertification process (Prince, 2002; Peters and Havstad, 2006). Rapid urbanization, intensive land use, large-scale ecological projects, and significant climate variation have made desertification dynamics more complicated, especially in the past 30 years (Zhang et al., 2012; D'Odorico et al., 2013; Wang, 2014; Xu et al., 2014). Thus, modeling desertification dynamics as a function of climatic variations and human activities is necessary in order to predict desertification risk, evaluate the impact of climate change, and support policy-making for desertification rehabilitation.

Numerous studies have attempted to predict and simulate desertification dynamics at different temporal-spatial scales (Van

\footnotetext{
* Corresponding author.

E-mail address: shaoqq@lreis.ac.cn (Q. Shao).
}

Delden et al., 2007; Ibanes et al., 2008; Helldén, 2008; Feng et al., 2010; Rasmy et al., 2010). For example, some studies used regression models, Markov models, or Cellular Automata (CA) models to simulate desertification by considering the statistical relationship between desertification dynamics and driving forces in a certain historical period (Liu et al., 2008; Ding et al., 2009; Feng et al., 2010). Although these models have a robust statistical basis, they are limited in their ability to explain the process of desertification, especially when modeling the impact of social driving factors and supporting policy-making. Furthermore, these models assumed that these relationships will not change in the future. Desertified lands represent open and complex systems. Multi-level feedbacks and non-linear impacts are two important characteristics of the desertification driving process (Peters and Havstad, 2006; Veron et al., 2006). For example, the interactions in the livestock-grasssoil system are extremely important for desertification at small scales (Hahn et al., 2005; Ibanez et al., 2007), but the effect of these interactions will be enhanced or weakened within a large-scale analysis that incorporates climate variation and other human activities. With the development of systems theory, an increasing number of studies are attempting to simulate desertification using the method of System Dynamics (SD). As a classical SD model, the 
predator-prey model has been frequently used to construct the relationship between humans (predator) and natural resources (prey) in rangeland in order to stimulate desertification dynamics. In 1995, Puigdefábregas developed a desertification model using the predator-prey approach that considered the effect of a closed grazing system and human migration (Puigdefábregas, 1995). Due to its good scalability, the predator-prey model was gradually enlarged, especially the predator component (Puigdefábregas, 1998; Ibanes et al., 2008; Helldén, 2008; Rasmy et al., 2010). For example, Helldén (2008) developed a human-environment twolevel coupled predator-prey model to simulate desertification dynamics in Sahelian; in this model, population stock was described as a function of growth rate, death rate, and resource-dependent migration. Rasmy et al. (2010) developed a dynamic simulation model of desertification in Egypt by considering the relationship among people, livestock, and plant cover. With the increasing demand for policy-support in regional and catchment environment management, simulation of desertification has often been included as one of the functions of a more comprehensive system models. Van Delden et al. (2007, 2009, 2011) designed a policy-support system for river basin management based on a multi-scale dynamic spatial model of socio-economic and physical processes, and this model included the simulation of land degradation and desertification.

Nevertheless, the SD method still faces some limitations when applied to desertification simulation. For example, several previous studies considered the research region as a whole when developing SD models for desertification simulation (Helldén, 2008; Rasmy et al., 2010). These models neglected the spatial heterogeneity of desertified lands as well as regional-scale driving forces. Furthermore, the degree of desertification was not considered in most simulations. Determining the desertification degree would aid in identifying the structural changes of desertified lands, assessing the effect of policies, and producing more detailed spatial planning for desertification control.

In contrast to classic system dynamic models, a spatial system dynamic (SSD) model can construct the linkage of SD variables to Geographical Information System (GIS), including both data association as well as semantic association (Zhang, 2008; Neuwirth et al., 2015). However, few studies have focused on developing an SSD model for desertification simulation at a regional scale that considers the effect of different natural and social factors (Van Delden et al., 2007). Therefore, this study attempts to develop an SSD model for desertification simulation by combining multi-level interactions between natural factors and socio-economic driving forces. We then apply the model to a typical region suffering desertification in China, the city of Ordos, to simulate desertification dynamics from 2011 to 2030 . This model will hopefully support the desertification control policies of the local government.

\section{Study area}

The city of Ordos is located in the southwest of the Inner Mongolia Autonomous Region of China, with the range of $37^{\circ}$ $41^{\prime}-40^{\circ} 51^{\prime} \mathrm{N}$ and $106^{\circ} 42^{\prime}-111^{\circ} 31^{\prime} \mathrm{E}$. Ordos has an area of approximately $86,752 \mathrm{~km}^{2}$ and had a population of roughly 1,480,000 in 2010 (Fig. 1). Ordos belongs to the arid and semi-arid transition zone, and is subject to a temperate continental climate. The annual rainfall ranges between 170 and $450 \mathrm{~mm}$. The rainfall increases along a gradient from west to east, and the majority of precipitation occurs during the period between July and September. The average annual temperature in this region ranges between 5.3 and $8.7^{\circ} \mathrm{C}$, and the annual actual evaporation ranges from 2000 to $3000 \mathrm{~mm}$. Moreover, over 40 days per year have wind speeds exceeding 8 on the expanded Beaufort wind scale.
Temperate steppe, temperate deciduous scrubs, steppe shrub desert, and desert characterize the typical vegetation and landscape in Ordos. Arenosols, Kastanozems, and Cambisols are the typical soil types in this region.

Ordos is also an ecologically fragile region with the Mu Us sandy land and Qubqi desert covering approximately $43,000 \mathrm{~km}^{2}$ and accounting for nearly $50 \%$ of the whole region. The dry climate conditions and long history of excessive human activity, including overgrazing, over cultivation, and overcutting, have made desertification a serious environment problem in this region. In order to combat desertification, the national and local governments have launched a series of ecological protection projects and policies over the past several decades, such as the Natural Forest Protection Project, the Grain-for-Green Project, rangeland enclosure, policy that forbids grazing, and large-scale afforestation (Huang et al., 2013; Wang et al., 2013). Although these projects and policies have played an important role in desertification reversal, the desertification situation in Ordos is still severe.

\section{Model}

\subsection{Model framework}

In contrast with other ecological and geographical parameters, desertification is only a description of land status, and it cannot be directly measured using conventional tools and units. Thus, it is necessary to select a common indicator that can reflect desertification status and that can be used as an intermediate variable to model the relationship between driving forces and desertification. Additionally, this indicator should be modeled using spatial data. As one of the most important indicators of ecosystems, vegetation Net Primary Production (NPP) is the predominant method used to measure desertification and its dynamics (Prince, 2002). Meanwhile, NPP can also be used to quantify the impact of different driving forces, such as climate, land use, pasturage, and afforestation (Haberl et al., 2007; Xu et al., 2010; Mu et al., 2013). NPP can also be retrieved via remote sensing images. Therefore, NPP is selected as the indicator for desertification modeling in this study.

According to the definition of desertification by UNCCD and the local conditions in Ordos, the selected driving forces for modeling the natural and anthropogenic impacts on desertification were climate, soil water, population, economic development, pasturage, and land use. By determining the impacts and feedback loops among driving forces and NPP, desertification status and degree can be modeled according to the relationship between NPP and different desertification grades. The framework of the desertification simulation model is shown in Fig. 2. The present model version simulates desertification from 2000 to 2030, using a temp-step of one year. The simulation results from 2000 to 2010 were used to validate the model, and the simulation results from 2011 to 2030 were used to predict desertification and assess the role of different driving forces.

\subsection{Individual model components}

\subsubsection{Climate}

Climate is a leading factor in triggering and expanding desertification. In this study, the selected climate parameters were rainfall, temperature, and sun duration. Owing to the spatial extent of the study area, the influence of land surface change on climate was not considered in this study. Therefore, we treated climate as an independent driving force that is only determined by historical status and man-made adjustment in the simulations of future scenarios. For the model calibration and validation, the climate data sets were obtained from the records of meteorological stations. For the 


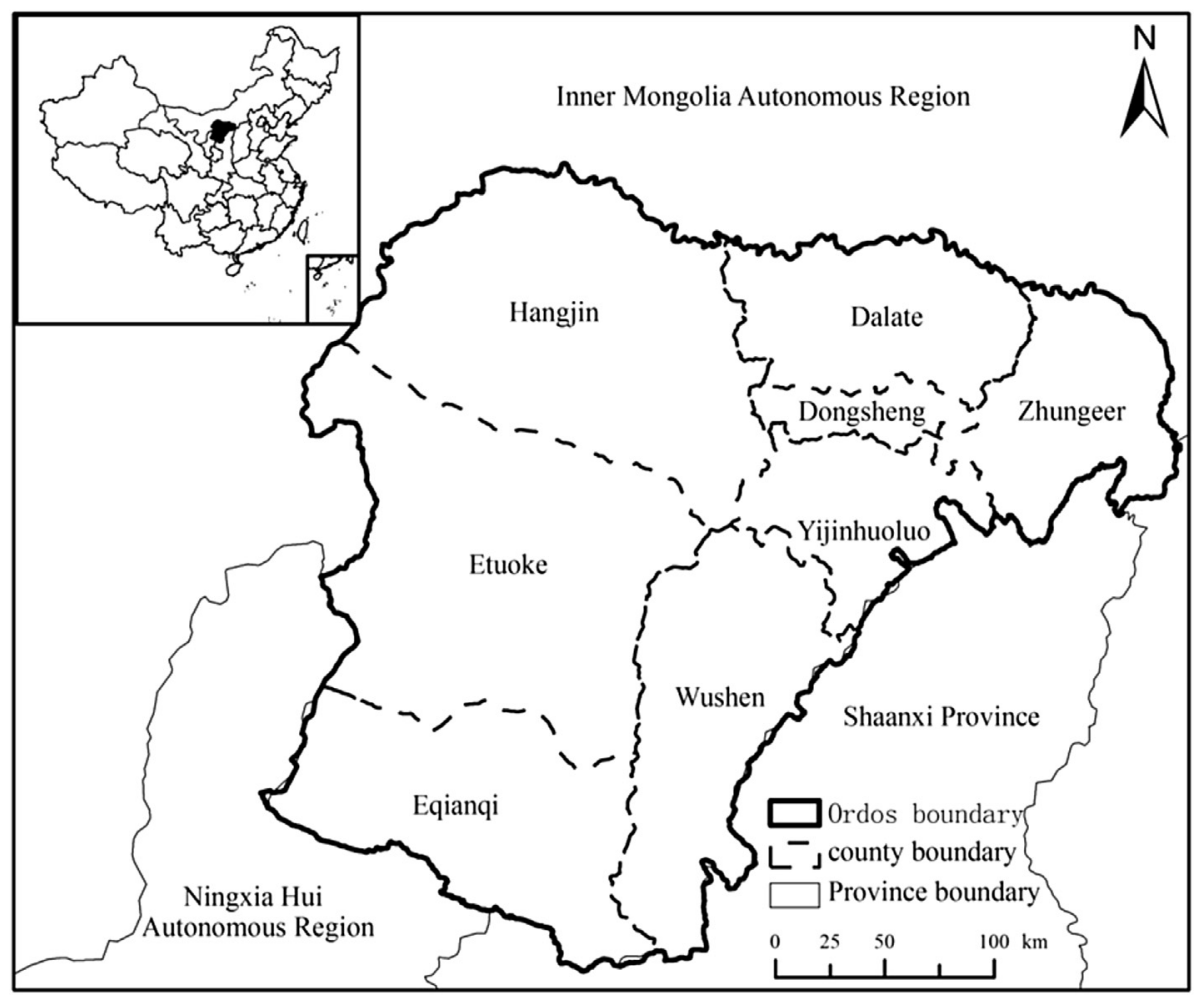

Fig. 1. The location of Ordos, China.

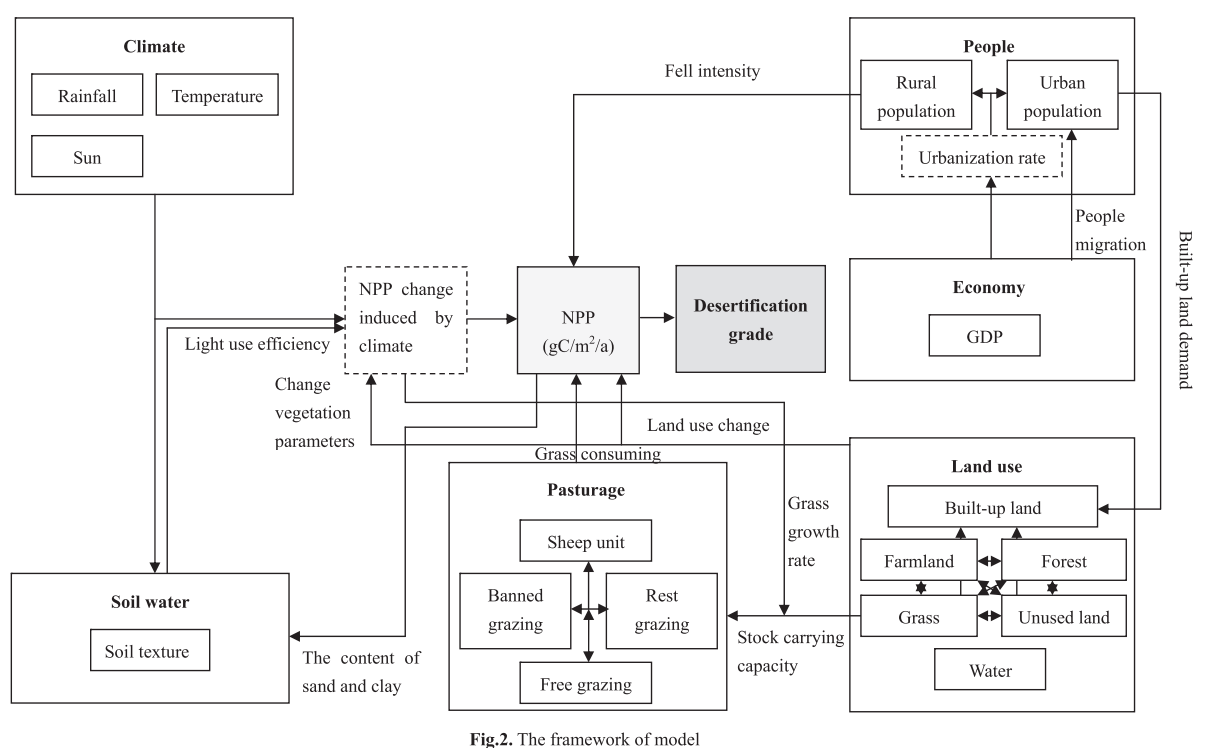

Fig. 2. The framework of model.

simulations of future scenarios, the climate data sets were produced according to the model settings. The climate stimulation utilized a monthly time-step.

\subsubsection{Soil water}

Soil water content is a limiting factor for vegetation growth, especially in arid and semi-arid regions, and soil water content is directly influenced by climate and soil texture. As a feedback mechanism, the change in vegetation will alter the physical and chemical characteristics of soil including the content of sand and clay, which would also have an impact on soil water. In this study, the soil water was simulated by using a classical soil water model (Saxton et al., 1986; Potter et al., 1993; Field et al., 1995), which was calculated according to the potential evaporation, rainfall, and soil texture. This module has a monthly time-step. The main equations for soil water simulation are listed below.

When rainfall was lower than potential evaporation in a specific month:

$\operatorname{soilm}_{t}=\max \left(\operatorname{soilm}_{t-1}-(\right.$ pet - rain $\left.) \times r d r, 0\right)$ 
When rainfall was higher than potential evaporation in a specific month:

$\operatorname{soilm}_{t}=\min \left(\operatorname{soilm}_{t-1}+(\right.$ rain - pet $\left.), w f c\right)$

where soilm $_{t}$ is the soil water content in month $t$; pet is the potential evaporation, which is determined by temperature in this study; rain is the rainfall in month $t ; r d r$ is the relative dry ratio, which is determined by the content of sand and clay in soil; and $w f c$ is the soil saturated water content, which is also related to soil sand and clay content. In this study, the initial values of soil sand and clay content were obtained from a 1:1,000,000 regional vector soil map, but they are then changed according to the dynamics of NPP. Considering the high difficulty in modeling the impact of NPP on sand and clay content in a system dynamics method, a statistical method and lookup functions were used to compute the relationship between NPP and both soil sand and clay content by randomly selecting 100 points to extract values from NPP and soil map. Herein, NPP refers to the results retrieved from the Carnegie-AmesStanford-Approach (CASA) model with MODIS NDVI data, which was employed as known data in this study (for a detailed description see Section 3.2.8). The function for computing the impact of NPP on soil sand content is shown in Equation (3).

sand $_{t}(\%)=\left\{\begin{array}{cc}95 & N P P \leq 40 \\ -0.375 N P P_{t-1}+105 & 40<N P P \leq 80 \\ -0.1 N P P_{t-1}+88 & 80<N P P \leq 120 \\ -0.067 N P P_{t-1}+84 & 120<N P P \leq 180 \\ -0.005 N P P_{t-1}+72.9 & N P P>180\end{array}\right.$

where $s a n d_{t}$ is the soil sand content in year $t$; and $N P P_{t-1}$ is the NPP in year $t-1$.

\subsubsection{Potential vegetation NPP}

Potential vegetation NPP in this study denotes NPP that is only determined by climate variation without considering the disturbance from human activities. For a pixel with a specific land use type, the potential vegetation NPP was only directly affected by climate condition and soil water content. Referencing the classical light use efficiency model for NPP modeling, the potential vegetation NPP was calculated as the multiplicative product of the Fraction of Absorbed Photosynthetically Active Radiation (FPAR), light use efficiency, and solar radiation (Tao et al., 2005). FPAR was determined by land use type of the previous year, which removes the effect of human disturbance in the current year. Light use efficiency was determined by the maximum light use efficiency, temperature, and soil water content; for instance, a higher soil water content results in a higher light use efficiency and enhanced ability to accumulate NPP. The maximum light use efficiency was also determined by land use and vegetation type in the previous year, and the soil water content comes from the soil water submodel.

$P N P P_{t}=S O L_{t} \times F P A R_{t-1} \times \varepsilon \times 0.5$

$\varepsilon=\varepsilon_{\max } \times T_{\varepsilon 1} \times T_{\varepsilon 2} \times W_{\varepsilon}$

Where $P N P P_{t}$ is the potential vegetation NPP in year $t$; $S O L_{t}$ is the solar radiation in year $t$; FPAR $R_{-1}$ is the FPAR in year $t-1 ; \varepsilon$ is the light use efficiency; and 0.5 is the coefficient for computing the absorbed solar radiation for vegetation growth (Piao et al., 2004); $\varepsilon_{\max }$ is the maximum light use efficiency; and $T_{\varepsilon 1}, T_{\varepsilon 2}$ and $W_{\varepsilon}$ are the effects of minimum temperature, maximum temperature and soil water on light use efficiency, respectively.

\subsubsection{Population}

Population has direct and indirect impacts on desertification. For example, a change in rural population would lead to a change in shrub cutting; meanwhile, a change in urban population would affect the demand for built-up land and would alter the land use patterns. In this study, the total population was determined by birth ratio, death ratio, and net immigration. Both birth ratio and death ratio were set to the average values between 2000 and 2010, and they can be adjusted in simulations according to the following function:

$$
\begin{aligned}
& \text { population }_{t}=\text { population }_{t-1} \times(1+\text { birthratio }- \text { deathratio }) \\
& + \text { netimmigration }_{t}
\end{aligned}
$$

where population $_{t}$ is the total population in year $t$; population $_{t-1}$ is the total population in the previous year; birthratio is the birth ratio; deathratio is the death ratio; and netimmigration ${ }_{t}$ is the net immigration in year $t$.

The net immigration value was determined by per capita Gross Domestic Product (GDP), and the relationship between the two parameters was constructed according to statistical data (Table 1). Per capita GDP was also used to calculate the rural and urban population levels and thereby obtain the urbanization rate. For modeling the impact of rural population on vegetation, the yearly cutting amount per capita was set at $97.35 \mathrm{~kg}$ of dry wood on the basis of a previous study (Song et al., 2005). In this study, the rural population was equally distributed to each grassland grid. For simulating the impact of urban population on land use, the per capita demand for built-up land was treated as a constant with a value of $0.001 \mathrm{~km}^{2}$. This level was calculated according to the builtup land area and urban population in 2000 and 2010. The time-step of the population stimulation is one year.

\subsubsection{Economic development}

Economic development is treated as an exogenous variable in this model and is measured by GDP. GDP values used in this study are the real GDP adjusted to the monetary value in 2000, which is calculated via the nominal GDP and a deflation factor. The GDP growth rate was the only factor that adjusted the GDP in the simulation, which was calculated according to the statistical data. In this model, a lookup table was used to simulate the change in GDP growth rate, and this can be adjusted according to the settings of different scenarios. Since 2000, the economy of Ordos developed rapidly due to the large-scale extraction of energy and resources, such as coal and natural gas. The average GDP growth rate between 2000 and 2010 reached up to $28 \%$. However, a declining trend in the GDP growth rate has been observed in recent years, and the value in 2010 was only $15 \%$. The time-step of economic development stimulation is one year.

\subsubsection{Pasturage}

Pasturage is the most important production mode for local rural people, and it can affect desertification by consuming biomass and destroying the soil structure. In this model, the impact of grazing was determined by livestock population and the grazing policy. For simulating livestock population, only sheep and large animals (i.e., cattle and horses) were considered. Birth rate, live birth rate, death rate, slaughtering rate for self-subsistence, and rate of sales were used to calculate the annual total livestock population (Equation (7)). These parameters were collected from the Ordos Statistical Yearbook. In order to unify the impact of grazing, a standard sheep unit was adopted to measure the total number of sheep and large animals. The coefficients used to convert sheep and large animals to 
Table 1

Lookup table for per capita GDP and net immigration population, urbanization rate.

\begin{tabular}{|c|c|c|c|c|c|}
\hline & \multicolumn{5}{|c|}{ Per capita GDP (RMB) } \\
\hline & 10,000 & 20,000 & 50,000 & 100,000 & 500,000 \\
\hline Net immigration population (person) & 6000 & 8000 & 12,000 & 15,000 & 40,000 \\
\hline Urbanization rate $(\%)$ & 50 & 70 & 80 & 90 & 90 \\
\hline
\end{tabular}

sheep units were set according to the agricultural standards of China (NY/T 635-2002). The transfer coefficients for large animals, sheep older than one year, and sheep younger than one year were 5 , 1 , and 0.5 , respectively. The time-step of the livestock stimulation is one year.
(1) grazing policies are only applied in grassland areas;

(2) regions with lower NPP should be the first to be included in the banned grazing policy. For example, if the banned grazing ratio was set to 0.4 , regions with the lowest $40 \%$ of NPP among all grassland pixels would be classified as banned

livestock $k_{t}=$ livestock $k_{t-1} \times(1+$ birthrate $\times$ birthliverate - deathrate - slaughterate - salerate $)$

For grazing policy, banned grazing and rest grazing were the most important measures to control desertification that were launched by the central and local governments (Wang et al., 2013). Therefore, banned grazing ratio, rest grazing ratio, and free grazing ratio were the parameters used to represent the grazing policy and its adjustment. The sum of these three ratios equals 1 . The spatial range of the banned grazing region and the rest grazing region were divided based on the following assumptions (the procedures are illustrated in Fig. 3). grazing regions;

(3) regions in grassland with higher NPP are then divided into the rest grazing regions according to the rest grazing ratio;

(4) the remaining grassland is classified as the free grazing regions.

According to the grazing policy, all sheep units were equally distributed into each grid cell of rest and free grazing regions. For the rest grazing policy, rest grazing period and forage-livestock balance strategy were selected as two adjustable parameters to determine the effect of policy implementation. The rest grazing
Grassland
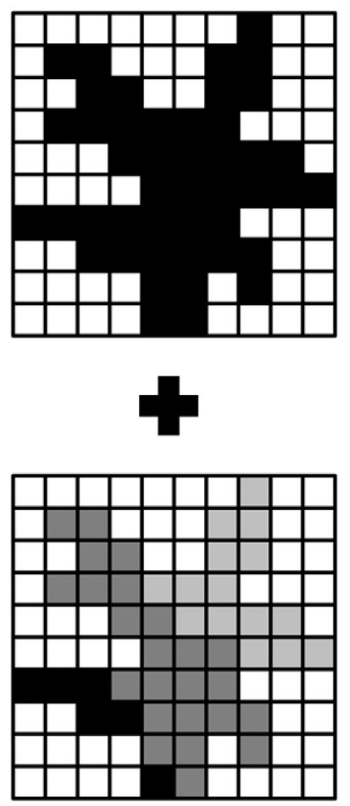

Grassland NPP

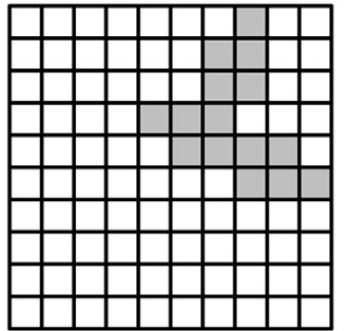

Banned grazing region grazing ratio
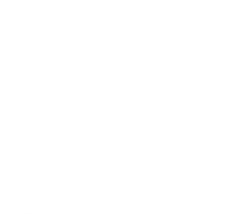

(2) Rest grazing ratio

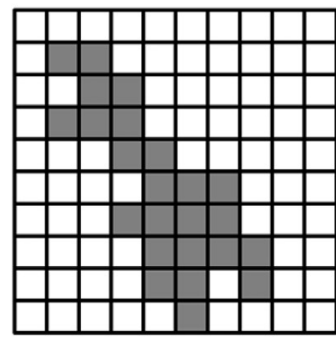

(3) Free grazing ratio

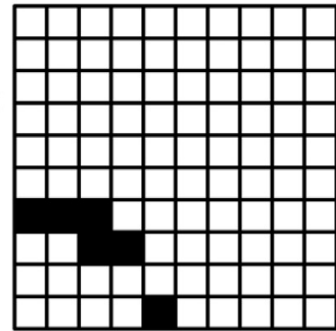

Rest grazing region

Free grazing region

Fig. 3. The sketch map of dividing grassland spatial range according to different grazing policies. 
period was calculated according to the number months that were selected for rest grazing, and the period was longer than 30 and less than 365 days. For Ordos, spring and early summer are always the best period for rest grazing. Forage-livestock balance was defined by two strategies in this model: adoption or non-adoption. If forage-livestock balance strategy was adopted, the actual number of sheep units in rest and free grazing regions was determined by the available NPP that can maintain natural recovery of grass. In this model, the ratio of available NPP to the total NPP was set to 0.5 (Holechek et al., 2001; Zhang et al., 2005). One sheep unit can consume $1.8 \mathrm{~kg}$ of standard dry grass with $14 \%$ water content per day according to the NY/T 635-2002 standard. The transfer ratio between dry matter and NPP was set at 0.45 in this study (Piao et al., 2004). If forage-livestock balance strategy was not adopted, the actual number of sheep units would not be limited by NPP. water); (2) the built-up land cannot be transitioned to other land use types; and (3) the transfer amounts of different land use types between 2000 and 2010 were calculated by comparing the land use maps from 2000 to 2010 that were derived from Landsat TM images. These transfer amounts can be adjusted for future scenarios to reflect the changes in desertification control policy. The transfer matrix for different land use types in Ordos from 2000 to 2010 is provided in Table 2.

The CA method was referenced to allocate the altered regions in this model. According to the main principle of CA (Batty and Xie, 1997; Batty et al., 1999; He et al., 2005; Li and He, 2008), the transition probability $\left(P_{i, A, B}\right)$ of pixel $i$ being converted from land use type $A$ to land use type $B$ is generated by calculating the land suitability $\left(S_{i, A, B}\right)$, neighborhood effect $\left(N_{i, A, B}\right)$, and land inheritance $\left(I_{i, A}\right)$.

$N P P_{i, t, g p}=\left\{\begin{array}{cc}0 & 1 \\ N P P_{\text {afterrest }} \times 0.5 & 2 \\ \text { sheep }_{\text {rest }} \times(365-\text { resttime }) \times 1.8 \times 10^{3} \times 0.86 \times 0.45 \times 10^{-6} & 3 \\ \text { sheep }_{\text {free }} \times 365 \times 1.8 \times 10^{3} \times 0.86 \times 0.45 \times 10^{-6} & 4\end{array}\right.$

where 1 denotes banned grazing; 2 indicates rest grazing with forage-livestock balance adoption; 3 refers to rest grazing with no forage-livestock balance adoption; and 4 denotes free grazing. $N P P_{i, t, g p}$ is the NPP consumed by grazing at pixel $i$ in

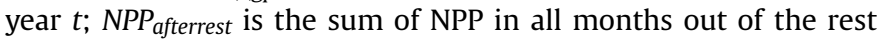
grazing period; sheep ${ }_{\text {rest }}$ is the number of sheep units under rest grazing; resttime is the rest grazing period; sheep $p_{\text {free }}$ is the number of sheep unit under free grazing.

In order to assess the effect of the grazing policy, the cost of banned grazing and rest grazing were considered and defined in this model. According to a public governmental report, the banned grazing cost is approximately 7425 RMB per year and the rest grazing cost is roughly 1845 RMB per 90 days.

\subsubsection{Land use}

Land use change, such as returning farm land to grassland and forest or planting grass in unused land, has a large impact on desertification (Wang et al., 2013). In this study, land use was classified into six types: built-up land, farm land, grassland, forest, unused land, and water (including rivers, lakes, and ponds). For land use simulation in this model, there are two issues that need to be addressed. The first is setting the total area of different land use types and their respective level of land use change; and the other is spatially allocating the land use transformations. For the first problem, three rules were set: (1) the total area of built-up land was determined by urban population, and increases in built-up land were mediated by the transition of other land use types (except for
$P_{i, A, B}=\left(1+S_{i, A, B}\right) \times\left(1+N_{i, A, B}\right)+I_{i, A}$

where $P_{i, A, B}$ is the transition probability. $S_{i, A, B}$ is the land suitability, which means the suitable degree for pixel $i$ transferring from land use type $A$ to $B . N_{i, A, B}$ is the neighborhood effect, which is used to measure the impact of land use type $B$ on the transition of land use type $A$ to $B$; a larger $N_{i, A, B}$ value indicates that pixel $i$ with land use $A$ has more $B$ neighbors in a fixed range, and this results in a higher transition probability from $A$ to $B . I_{i, A}$ is the land inheritance of the original land use type, which is set to 1 for all land use types in this study.

For land suitability, the distances from roads and slopes were used to calculate $S_{i, A, B}$, and the weight of these two factors was equal. If the pixel was close to a road, it was considered to have a higher transition probability. The effect of slope is different for different land use type. A lower slope increased the probability that land would transition to built-up land. A higher slope increased the probability of farm land transitioning to grassland or forest (the policy of returning farm land to grass and forest). A condition function was used to calculate the effect of slope, and details can be found in previous studies (He et al., 2005; Li and He, 2008). The neighborhood effect was calculated by passing a $3 \times 3$ sliding window across the binary maps of land use. The sum of every sliding window was calculated and assigned to the central pixel.

Table 2

Transfer matrix of different land use types in Ordos from 2000 to $2010\left(\mathrm{~km}^{2}\right)$.

\begin{tabular}{|c|c|c|c|c|c|c|c|}
\hline & & \multicolumn{6}{|l|}{2010} \\
\hline & & Farm land & Forest & Grass & Built-up land & Unused land & Water \\
\hline \multirow[t]{6}{*}{2000} & Farm land & 4176 & 2 & 272 & 48 & 64 & 17 \\
\hline & Forest & 19 & 1253 & 84 & 28 & 25 & 3 \\
\hline & Grass & 695 & 21 & 49,468 & 186 & 2705 & 201 \\
\hline & Built-up land & 14 & 0 & 6 & 790 & 2 & 1 \\
\hline & Unused land & 176 & 4 & 4977 & 51 & 19,375 & 99 \\
\hline & Water & 40 & 1 & 221 & 32 & 220 & 1592 \\
\hline
\end{tabular}


$N_{i, A, B}=\left(1-N_{i, A}\right) \times N_{i, B}$

where $N_{i, A}$ is the proportion of land use $A$ in the sliding window, and $N_{i, B}$ is the proportion of land use Bin the sliding window.

After calculating the transfer amount and transfer probability indices, pixels were selected in descending order of probability until the transfer amount was reached. The calculation sequence was built-up land, farm land, grass, forest, and then unused land. We assumed that the area of water would not change significantly over a long period or have a significant impact on desertification; there the area of water was fixed at a constant value (the value from 2000). The transfer of land use can also result in changes in desertification control costs. According to the statistical data, the cost of returning farm land to grass or forest was set to 600,000 $\mathrm{RMB} / \mathrm{km}^{2}$, and the cost of planting grass or forest in unused land was set to $8798 \mathrm{RMB} / \mathrm{km}^{2}$.

\subsubsection{Desertification}

In this module, there are two issues that need to be addressed. The first is to calculate the final NPP by synthesizing the impacts of the selected driving forces mentioned in above modules on NPP. The second is to classify and map desertification according to the range of NPP assigned to each desertification grade.

The final NPP was calculated according to the following formula:

$$
\begin{aligned}
N P P_{i, t}= & N P P_{i, t-1}+\Delta N P P_{i, t, c}+\Delta N P P_{i, t, l}-N P P_{i, t, g p}-N P P_{i, t, g c} \\
& +N P P_{i, t, g r}
\end{aligned}
$$

where $N P P_{i, t}$ is the final NPP in year $t$ at pixel $i$; $N P P_{i, t-1}$ is the final NPP in year $t-1$ at pixel $i ; \triangle N P P_{i, t, c}$ is the potential vegetation NPP change solely induced by climate change from year $t-1$ to $t$ without considering the impact of land use change; $\triangle N P P_{i, t, l}$ is the NPP change induced solely by land use from year $t-1$ to $t ; N P P_{i, t, g p}$ is the NPP consumed by grazing in grassland; $N P P_{i, t, g c}$ is the NPP consumed by the rural population for energy use in the grassland area; and $N P P_{i, t, g r}$ is the natural recovery of grassland after grazing and cutting.

For $N P P_{i, t-1}$, the baseline data for 1999 was obtained using the CASA model and the average MODIS NDVI data between 2000 and 2003 with $1 \mathrm{~km}$ resolution. The CASA model is a classical light-useefficiency model for NPP simulation based on the product of absorbed photosynthetically active radiation (APAR), the max lightuse efficiency and its limiting factor, which has been proven to be reliable in China. The details of the CASA model can be found in the literature (Potter et al., 1993; Field et al., 1995; Tao et al., 2005). In this study, the NPP data from the CASA model was also used to quantify the parameters of sub-modules, such as soil water, pasturage, and land use. $\triangle N P P_{i, t, l}$ was calculated by comparing the land use map in year $t$ and $t-1$, and the NPP of each land use type is set according to the average value from 2000 to $2010 . N P P_{i, t, g p}$ was calculated by referencing equitation (8). NPP i,t,gc was calculated according to the rural population, grass remove level per person, and ecological protection policy (presence or absence of policy forbidding grass removal). $N P P_{i, t, g r}$ was calculated by referencing the classic pasture growing model (Holechek et al., 2001).

$N P P_{i, t, g r}=r x\left(1-\frac{x}{k}\right)$

where $r$ is the innate increase rate under a specific climate condition, which is determined by the ratio of $N P P_{i, t, c}$ to $N P P_{i, t-1, c} ; x$ is the NPP in year $t$; and $k$ is the maximum value of NPP in grassland. In this study, $k$ is set to $140 \mathrm{gC} / \mathrm{m}^{2} /$ a based on the average NPP value of grassland with non-desertification.

According to the most widely used desertification classification system in China (Wang et al., 2004, 2011), the desertification was classified into five grades in this study: non-desertification, low desertification, medium desertification, high desertification, and severe desertification. Three steps were used to establish the NPP range of different desertification grades in this study:

(1) monitoring of the desertification statuses in Ordos in 2000 and 2010 using a Decision Tree model and Landsat TM/ $\mathrm{ETM}+$ images, which has been proved to be accurate in previous studies (Xu et al., 2009);

(2) randomly selecting 100 points for each desertification grade to extract the values of NPP in 2000 and 2010, retrieved from the CASA model;

(3) establishing the NPP range of different desertification grades by referencing the average value, standard deviation, and the frequency map of the extracted NPP values.

In this study, the NPP range of non, low, medium, high, severe desertification is $>180 \mathrm{gC} / \mathrm{m}^{2} / \mathrm{a}, 180-120 \mathrm{gC} / \mathrm{m}^{2} / \mathrm{a}, 120-80 \mathrm{gC} / \mathrm{m}^{2} /$ $\mathrm{a}, 80-40 \mathrm{gC} / \mathrm{m}^{2} / \mathrm{a}$, and $<40 \mathrm{gC} / \mathrm{m}^{2} / \mathrm{a}$, respectively. In order to improve the simulation accuracy, the built-up land and water were classified as non-desertification before using the NPP criteria. In order to make it convenient and direct for governors to understand and assess the comprehensive status of desertification in Ordos, the desertification degree index was designed and calculated by coding the five desertification grades from 5 to 1 according to the severity and then using the proportion of grades as the weight.

$$
\begin{aligned}
\text { DDI }= & \text { non } \% \times 5+\text { low } \% \times 4+\text { medium } \% \times 3+\text { high } \% \times 2 \\
& + \text { severe } \% \times 1
\end{aligned}
$$

where $D D I$ is the desertification degree index. non\%, low\%, medium $\%$, high\%, and severe\% are the percentage of non, low, medium, high, and severe desertification land area to the whole area of Ordos.

\subsection{Data collection and processing}

In this study, social and economic data was collected from the Ordos Statistical Yearbooks, including total population, urban population, rural population, birth rate, death rate, GDP, total livestock number, and number of livestock that was sold and slaughtered by farmers. The monthly-averaged meteorological data, including rainfall, temperature, and sunshine duration, from 1980 to 2010 as recorded by meteorological stations in and around Ordos was obtained from the China Meteorological Administration. A $1: 1,000,000$ vector vegetation map and soil map of China and the related attributes were obtained from the Data Center for Resources and the Environmental Sciences at the Chinese Academy of Sciences. For NPP calculation, MODIS 16-day composited NDVI (MOD13A1) data was downloaded from the Earth Resources Observation and Science (EROS) Center of the United States Geological Survey. This data was further composited using the Maximum Value Composite (MVC) method to produce the monthly NDVI from 2000 to 2010. In order to produce land use maps, Landsat ETM $+/$ TM images acquired from June to September in 2000 and 2010 were also collected from EROS, and a human-computer interactive visual interpretation approach was employed to classify land use types. According to the requirements of developing an SSD model, all of the climate, vegetation, soil, and land use data sets were converted or re-sampled into grid data with a $1 \mathrm{~km} \times 1 \mathrm{~km}$ resolution. The data used in each module is listed in Table 3. 
Table 3

Data item used in different modules.

\begin{tabular}{|c|c|c|}
\hline Module & Data item & Data source \\
\hline Climate & Monthly-averaged rainfall, temperature, sunshine duration & China Meteorological Administration \\
\hline Soil water & $\begin{array}{l}\text { Monthly-averaged rainfall, temperature, sunshine duration; } \\
\text { soil sandy and clay content; NPP in previous year }\end{array}$ & $\begin{array}{l}\text { China Meteorological Administration; Data Center for } \\
\text { Resources and the Environmental Sciences at the Chinese } \\
\text { Academy of Sciences; Modeled NPP in previous year }\end{array}$ \\
\hline Potential vegetation NPP & $\begin{array}{l}\text { Monthly-averaged rainfall, temperature, sunshine duration; } \\
\text { soil water content; land use type and area }\end{array}$ & $\begin{array}{l}\text { China Meteorological Administration; Model soil water; } \\
\text { Modeled land use }\end{array}$ \\
\hline Population & $\begin{array}{l}\text { Total population, urban population, rural population, birth } \\
\text { rate, death rate, GDP; land use type and area; NPP in } \\
\text { previous year }\end{array}$ & $\begin{array}{l}\text { Ordos Statistical Yearbooks; Modeled land use; Modeled } \\
\text { NPP in previous year }\end{array}$ \\
\hline Economic development & GDP, GDP growth rate & Ordos Statistical Yearbooks \\
\hline Pasturage & $\begin{array}{l}\text { Total number of sheep and large animal; birth rate, live } \\
\text { birth rate, death rate, slaughtering rate, sale rate of sheep } \\
\text { and large animal; banned grazing rate, rest grazing rate, free } \\
\text { grazing rate, rest grazing period, forage-livestock balance } \\
\text { strategy; land use type and area; NPP }\end{array}$ & $\begin{array}{l}\text { Ordos Statistical Yearbooks; Model setting; Modeled land } \\
\text { use; Modeled NPP in previous year }\end{array}$ \\
\hline Land use & $\begin{array}{l}\text { Urban population; land use type and area; TM images; road, } \\
\text { slope }\end{array}$ & $\begin{array}{l}\text { Ordos Statistical Yearbooks; Modeled land use; Earth } \\
\text { Resources Observation and Science Center of the United } \\
\text { States Geological Survey; Data Center for Resources and the } \\
\text { Environmental Sciences at the Chinese Academy of Sciences }\end{array}$ \\
\hline Desertification & $\begin{array}{l}\text { NPP in previous year, potential vegetation NPP, NPP change } \\
\text { induced by land use, NPP consumed by grazing, NPP } \\
\text { removed by rural population, NPP natural recovery of } \\
\text { grassland }\end{array}$ & $\begin{array}{l}\text { Modeled results from sub-models, including potential } \\
\text { vegetation, population, pasturage land use and } \\
\text { desertification }\end{array}$ \\
\hline
\end{tabular}

\subsection{Model development environment}

In this study, the spatial system dynamic model for desertification simulation was designed using the development platform with Microsoft Visual Studio.Net 2008 development environment (C\#) and ArcGIS Engine 9.3. According to the model framework, 8 modules were developed and each of them was designed to interface. This allowed the construction of linkages among modules to achieve the system dynamic process.

\subsection{Model calibration, validation and sensitivity analysis}

The model developed in this study is calibrated with data from different sources, such as historical statistical yearbooks as well as soil and vegetation maps of Ordos. For some social and economic parameters that were derived via a lookup function (such as net immigration population, urbanization rate, and per GDP), the inflexion points and parameter values of the lookup function were adjusted constantly until the error between simulation result and historical data reached a reasonable level. Some state variables with no public data source, such as initial soil water, were calibrated by stable condition and historical data simulation. In the soil water simulation, the initial soil water is first set to the saturated status, and then simulations are run for a number of years under the average climate condition over the past 30 years until a stable condition is obtained (the error between simulation at time $t$ and $t-1$ is less than $1 \%$ ). The stable condition is then set to the new initial soil water, and the real climate condition is subsequently employed to simulate the soil water dynamics.

In this study, the simulated results from 2000 to 2010 were used to validate the model via comparison with the data from Yearbooks and other classical model or method. Generally, the validation was classified into two types: the validation of intermediate parameters (including total population, livestock number, and NPP) and the validation of final simulation results (e.g., desertification degree). For the validation of intermediate parameters, the data of total population and livestock number from the Ordos Statistical Yearbooks 2000-2010 were used to validate the model results. Considering the difficulty of acquiring NPP data at a regional scale via investigative methods, NPP (2000-2010) retrieved from the
CASA model, which has been validated and proven to be effective in the research region (Xu et al., 2010), and were selected to validate the NPP modeled in this study. Root Mean Square Error (RMSE) and the coefficient of determination $\left(R^{2}\right)$ were calculated to assess the accuracy of these intermediate parameters. Desertification degree is also difficult to measure directly; therefore, the data from classical desertification monitoring methods were employed in the validation. In this study, a Decision Tree model with Landsat TM/ ETM + images was used to acquire the value of desertification degree. To assess the accuracy, 100 examination points were randomly selected to extract values from the simulated results and the data from Decision Tree model in 2005 and 2010. The overall accuracy of simulation is defined by the ratio of correctly classified points to the total number of points.

Sensitivity analysis is an effective way to understand and evaluate models by determining the model output response to changes in input variables (Salteli and Annoni, 2010). In this study, the sensitivity analysis was conducted by sequentially varying one input parameter while keeping all others fixed. The sensitivity degree for a specific parameter was defined as the change of NPP in 2030 when a parameter increased by $10 \%$ from the baseline of the average value (Yin et al., 2010). The equation for sensitivity degree calculation is listed below.

$S=\frac{\Delta N P P_{2030}}{\Delta X} \times \frac{|X|}{N P P_{2030}}$

where $S$ is the sensitivity degree of parameter $X ; X$ is average value over the past 30 years of parameter $X ; \Delta X$ is the $10 \%$ increase of parameter $X ; N P P_{2030}$ is the simulated NPP value in 2030 under the baseline scenario, i.e., all model parameters were set as the average value over past 30 years and did not change during the simulation process. $\triangle N P P_{2030}$ is the relative change in $N P P_{2030}$ induced by $\Delta X$. Due to the dimensionless nature of $S$, it can be used to measure the relative impact of parameters with different units. A higher value of $S$ indicates a greater impact of the input parameter.

\subsection{Scenario setting for desertification simulation}

In order to simulate the desertification dynamics in Ordos under 
Table 4

Values or change of some key parameter from 2011 to 2030 under different scenarios.

\begin{tabular}{|c|c|c|c|c|c|c|c|c|c|}
\hline & $\begin{array}{l}\text { Climate } \\
\text { variation }\end{array}$ & $\begin{array}{l}\text { Human } \\
\text { activity }\end{array}$ & Rain & Temperature & Growth rate of GDP & $\begin{array}{l}\text { Grazing forbidden } \\
\text { ratio }\end{array}$ & $\begin{array}{l}\text { The behavior } \\
\text { after rest } \\
\text { razing }\end{array}$ & $\begin{array}{l}\text { Farm land return } \\
\text { to grass or forest } \\
\text { land }\end{array}$ & $\begin{array}{l}\text { Unused land } \\
\text { planted grass }\end{array}$ \\
\hline 1 & \multicolumn{2}{|c|}{ Baseline scenario } & $-^{*}$ & - & - & - & - & - & - \\
\hline 2 & No change & Sustainable & - & - & $\begin{array}{l}12 \% \text { in } 2015 \text { and } \\
\text { decrease } 2 \% \text { every } 5 \\
\text { years }\end{array}$ & $\begin{array}{l}\text { Increase } 10 \% \text { every } \\
5 \text { years }\end{array}$ & Balance & $\begin{array}{l}\text { Increase } 5 \% \text { very } 5 \\
\text { years }\end{array}$ & $\begin{array}{l}\text { Increase } 5 \% \\
\text { very } 5 \text { years }\end{array}$ \\
\hline 3 & No change & Unsustainable & - & - & $\begin{array}{l}\text { keeps at } 15 \% \text { from } \\
2010 \text { to } 2030\end{array}$ & $\begin{array}{l}\text { decrease } 10 \% \text { every } \\
5 \text { years }\end{array}$ & Freely grazing & $\begin{array}{l}\text { Decrease } 5 \% \text { very } 5 \\
\text { years }\end{array}$ & $\begin{array}{l}\text { Decrease } 5 \% \\
\text { very } 5 \text { years }\end{array}$ \\
\hline 4 & More humid & No change & $\begin{array}{l}\text { Increase } 5 \% \text { every } 5 \\
\text { years }\end{array}$ & - & $\begin{array}{l}\text { Keeps at } 15 \% \text { from } \\
2010 \text { to } 2030\end{array}$ & - & Balance & - & - \\
\hline 5 & More humid & Sustainable & $\begin{array}{l}\text { Increase } 5 \% \text { every } 5 \\
\text { years }\end{array}$ & - & $\begin{array}{l}12 \% \text { in } 2015 \text { and } \\
\text { decrease } 2 \% \text { every } 5 \\
\text { years }\end{array}$ & $\begin{array}{l}\text { Increase } 10 \% \text { every } \\
5 \text { years }\end{array}$ & Balance & $\begin{array}{l}\text { Increase 5\% very } 5 \\
\text { years }\end{array}$ & $\begin{array}{l}\text { Increase } 5 \% \\
\text { very } 5 \text { years }\end{array}$ \\
\hline 6 & More humid & Unsustainable & $\begin{array}{l}\text { Increase } 5 \% \text { every } 5 \\
\text { years }\end{array}$ & - & $\begin{array}{l}\text { Keeps at } 15 \% \text { from } \\
2010 \text { to } 2030\end{array}$ & $\begin{array}{l}\text { Decrease } 10 \% \text { every } \\
5 \text { years }\end{array}$ & Freely grazing & $\begin{array}{l}\text { Decrease } 5 \% \text { very } 5 \\
\text { years }\end{array}$ & $\begin{array}{l}\text { Decrease } 5 \% \\
\text { very } 5 \text { years }\end{array}$ \\
\hline 7 & More arid & No change & $\begin{array}{l}\text { Increase } 0.5 \text { every } 5 \\
\text { years }\end{array}$ & - & $\begin{array}{l}\text { Keeps at } 15 \% \text { from } \\
2010 \text { to } 2030\end{array}$ & - & Balance & - & - \\
\hline 8 & More arid & Sustainable & - & $\begin{array}{l}\text { Increase } 0.5 \\
\text { every } 5 \text { years }\end{array}$ & $\begin{array}{l}12 \% \text { in } 2015 \text { and } \\
\text { decrease } 2 \% \text { every } 5 \\
\text { years }\end{array}$ & $\begin{array}{l}\text { Increase } 10 \% \text { every } \\
5 \text { years }\end{array}$ & Balance & $\begin{array}{l}\text { Increase } 5 \% \text { very } 5 \\
\text { years }\end{array}$ & $\begin{array}{l}\text { Increase } 5 \% \\
\text { very } 5 \text { years }\end{array}$ \\
\hline 9 & More arid & Unsustainable & - & $\begin{array}{l}\text { Increase } 0.5 \\
\text { every } 5 \text { years }\end{array}$ & $\begin{array}{l}\text { Keeps at } 15 \% \text { from } \\
2010 \text { to } 2030\end{array}$ & $\begin{array}{l}\text { Decrease } 10 \% \text { every } \\
5 \text { years }\end{array}$ & Freely grazing & $\begin{array}{l}\text { Decrease } 5 \% \text { very } 5 \\
\text { years }\end{array}$ & $\begin{array}{l}\text { Decrease } 5 \% \\
\text { very } 5 \text { years }\end{array}$ \\
\hline 10 & BLANK scenar & & - & - & $\begin{array}{l}\text { Keeps at } 15 \% \text { from } \\
2010 \text { to } 2030\end{array}$ & 0 & Freely grazing & 0 & 0 \\
\hline
\end{tabular}

* “-" means the factor would keep the same as the average value between 2000 and 2010.

different climatic and socio-economic conditions and assess the effect of different desertification prevention policies, different scenarios were defined by considering the probable future climate changes and socio-economic development strategies. For climate change, three probable scenarios were defined: (1) no significant change, (2) an increase in humidity, and (3) an increase in aridity. For socio-economic development strategy, we defined the following three scenarios: (1) no significant change, (2) a sustainable strategy, and (3) an unsustainable strategy. By combining the future scenarios of climate and socio-economic development, there are 9 comprehensive scenarios. Additionally, we created an extreme scenario that assumes the abandonment all of ecological protection policies and projects after 2010 . This scenario is termed the "blank scenario," and it can be used to examine the effect of these policies and projects on desertification control. The alteration of key parameter values under different scenarios are explained and listed in Table 4.

\section{Results}

\subsection{Model accuracy assessment}

According to Table 5, the simulation accuracy of intermediate parameters is very high, especially for the total population. However, the simulation accuracy for total number of sheep and large animals is relatively lower. For the NPP simulation (Fig. 4), the $\mathrm{R}^{2}$ reached a maximum of 0.93 , but the RMSE was relatively higher at approximately $28 \mathrm{gC} / \mathrm{m}^{2} / \mathrm{a}$. As an indicator of desertification degree, the higher RMSE of NPP impacts the overall accuracy of desertification simulation. However, this RMSE is acceptable considering the NPP range of different desertification degrees and the high number of parameters in the NPP modeling. The changes in average NPP of Ordos between 2000 and 2010 predicted by the CASA model and our model were also compared (Fig. 5). Although the NPP values of our model were lower and more stable than the CASA results, our model could simulate the same trend. Both models showed an increasing trend of NPP between 2000 and 2010, which corresponds to the actual situation (Mu et al., 2013).
Table 5

$\mathrm{R}^{2}$ and RMES of some key parameters for model validation.

\begin{tabular}{lcccc}
\hline & Total population & Sheep & Big animal & NPP \\
\hline $\mathrm{R}^{2}$ & 0.99 & 0.97 & 0.81 & 0.93 \\
$\mathrm{RMSE}$ & 19,656 & 463,540 & 27,495 & 28 \\
\hline
\end{tabular}

The confusion matrix was constructed by comparing the modeled desertification degree and the monitoring data from Decision Tree model (Table 6). According to the statistical results, the overall accuracy of desertification degree was approximately $83 \%$. Medium and high desertification areas had the lowest accuracy among the five desertification grades. This might be attributed to the higher RMSE of NPP simulation. The accuracy of simulated severe desertification areas was higher than the other categories,

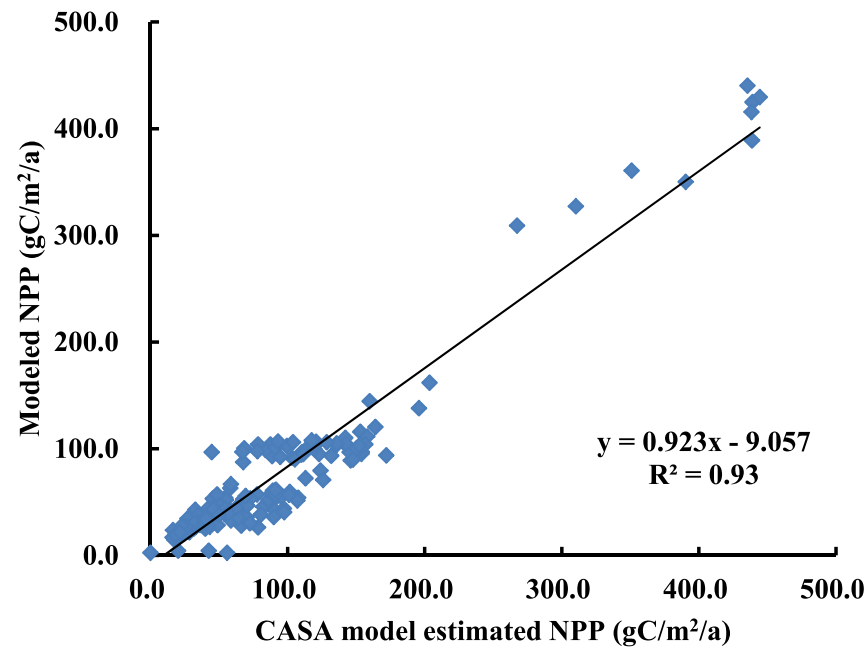

Fig. 4. The comparison of modeled NPP in this study and the CASA model estimated NPP. 


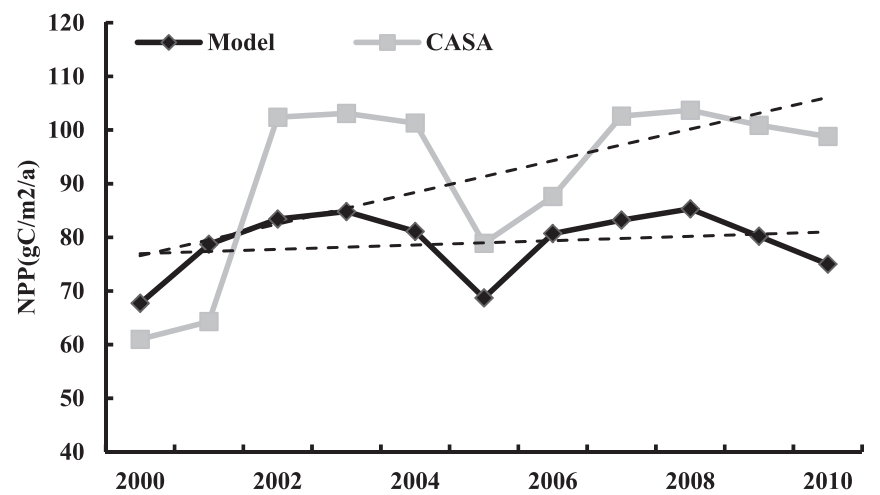

Fig. 5. The change of averaged NPP between 2000 and 2010 derived from SSD model and CASA.

reaching up to $100 \%$. In general, the accuracy of the model developed in this study is acceptable, and it can be used for further analysis.

\subsection{Model sensitivity analysis}

The sensitivity analysis results for some key parameters in this model are listed in Table 7. Among all of these parameters, rainfall showed the highest sensitivity. The $S$ value of rainfall reached 0.36 , which meant a $10 \%$ increase of rainfall would lead to a $3.6 \%$ increase of NPP in 2030. In contrast, the sensitivities of social and economic parameters were lower than climate parameters. Meanwhile, social and economic parameters also showed significant differences in sensitivity. Banned grazing rate and planting grass in unused land had positive $S$ values that were relatively higher than other social and economic parameters. However, population birthrate, GDP growth rate and per constructed land demand had relatively lower sensitivity in this model.

\subsection{Desertification simulation in Ordos}

According to the settings of the scenarios, the desertification dynamics in Ordos from 2011 to 2030 were simulated using the model developed in this study. As shown in Fig. 6 and Table 8, climate change and human activities played different roles in desertification dynamics and resulted in Ordos exhibiting different desertification characteristics in the simulations of future scenarios. According to the comparison between the baseline scenario and the three more humid scenarios, a more humid climate would decrease desertified land by $2000 \mathrm{~km}^{2}$ from 2011 to 2030 without any change in desertification prevention policies. Although sustainable strategy coupled with a more humid climate would lead to reversal of desertification before 2020, different desertification prevention strategies did not differ significantly with regard to reduction in desertified land area in 2030. This was mainly attributed to the rapid increase in pasturage pressure after 2025. The comparison of the baseline scenario to the three more arid scenarios showed that the more arid climate would accelerate desertification expansion in Ordos. Under the more arid climate condition, the sustainable development strategy and active prevention policy would significantly reduce desertification degree and achieve the same status as the baseline scenario in 2028.

For the two scenarios with climates that did not significantly change, both sustainable and unsustainable development strategies led to a reduction of desertified land in Ordos by 2030. This is mainly attributed to the good climatic conditions between 2000 and 2010. Comparatively, the sustainable development strategy was more effective in controlling desertification than the unsustainable development strategy. However, due to the rapid increase in pasturage pressure after 2025, the sustainable development strategy did not prevent increases in desertification degree during the last five years of the simulation. The comparison between the baseline scenario and blank scenario indicated that if the desertification control projects and policies were abolished after 2010, the desertification degree in Ordos would increase to high desertification in 2015. This is 15 years ahead of the baseline scenario.

Different scenarios lead to different desertification prevention costs (the sum of the cost from banned grazing, rest grazing, returning farm land to grass, and planting grass or forest in unused land), and the cost of sustainable development strategies was much higher than the unsustainable development strategies. According to the accumulated desertification prevention cost statistics

Table 6

The confusion matrix of the modeled desertification degree and the monitoring data from Decision Tree model.

\begin{tabular}{|c|c|c|c|c|c|c|}
\hline & & \multicolumn{5}{|c|}{ Modeled data } \\
\hline & & Non & Low & Medium & High & Severe \\
\hline \multirow[t]{5}{*}{ Monitoring data from Decision Tree model } & Non & 26 & 2 & 2 & 0 & 0 \\
\hline & Low & 0 & 10 & 1 & 1 & 0 \\
\hline & Medium & 0 & 2 & 62 & 6 & 4 \\
\hline & High & 4 & 0 & 2 & 36 & 8 \\
\hline & Severe & 0 & 0 & 0 & 0 & 34 \\
\hline
\end{tabular}

Table 7

$\mathrm{NPP}\left(\mathrm{gC} / \mathrm{m}^{2} / \mathrm{a}\right)$ change induced by parameter adjustment and their sensitivity degree.

\begin{tabular}{|c|c|c|c|c|c|c|c|}
\hline Parameter & 2010 & 2015 & 2020 & 2025 & 2030 & $\Delta N P P_{2030}$ & $\mathrm{~S}$ \\
\hline Baseline & 103.79 & 101.01 & 97.32 & 92.19 & 93.24 & 0.00 & 0.00 \\
\hline Rainfall & 103.79 & 104.29 & 100.74 & 95.61 & 96.64 & 3.40 & 0.36 \\
\hline Temperature & 103.79 & 102.75 & 99.13 & 93.98 & 95.22 & 1.98 & 0.21 \\
\hline Population birthrate & 103.79 & 101.01 & 97.31 & 92.15 & 93.19 & -0.05 & -0.01 \\
\hline GDP growth rate & 103.79 & 101.01 & 97.33 & 92.20 & 93.26 & 0.02 & 0.00 \\
\hline Banned grazing rate & 103.79 & 100.91 & 98.03 & 94.00 & 95.13 & 1.89 & 0.20 \\
\hline Rest grazing rate & 103.79 & 101.11 & 96.62 & 90.38 & 91.35 & -1.89 & -0.20 \\
\hline Per capital built-up land & 103.79 & 100.82 & 97.10 & 91.92 & 92.98 & -0.26 & -0.03 \\
\hline Return farm land to grass & 103.79 & 100.99 & 97.21 & 91.97 & 92.88 & -0.36 & -0.04 \\
\hline Plant grass in unused land & 103.79 & 101.08 & 97.76 & 93.09 & 94.15 & 0.91 & 0.10 \\
\hline
\end{tabular}



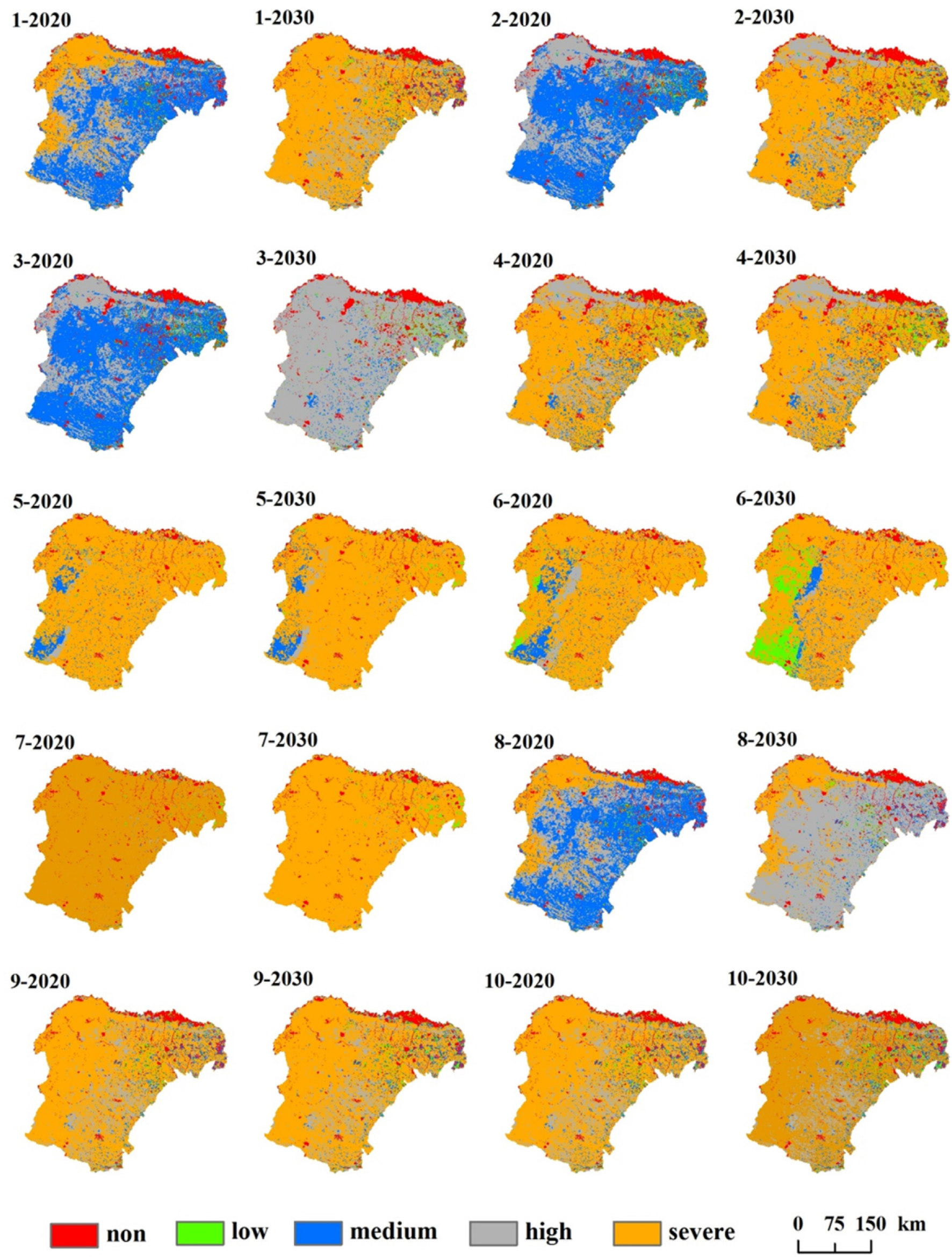

Fig. 6. The modeling result of 2020 and 2030 under different scenarios (1-2020 means modeling result of 2020 under scenario 1). 
Table 8

Area of different grades of desertified land $\left(\mathrm{km}^{2}\right)$ and desertification degree index under 10 scenarios.

\begin{tabular}{|c|c|c|c|c|c|c|c|c|c|c|c|c|c|c|c|}
\hline & \multicolumn{3}{|c|}{ Low desertification } & \multicolumn{3}{|c|}{ Medium desertification } & \multicolumn{3}{|c|}{ High desertification } & \multicolumn{3}{|c|}{ Severe desertification } & \multicolumn{3}{|c|}{$\begin{array}{l}\text { Desertification degree } \\
\text { index }\end{array}$} \\
\hline & 2010 & 2020 & 2030 & 2010 & 2020 & 2030 & 2010 & 2020 & 2030 & 2010 & 2020 & 2030 & 2010 & 2020 & 2030 \\
\hline 1 & 1389 & 1597 & 1654 & 36,783 & 38,970 & 3851 & 23,044 & 23,145 & 10,142 & 20,783 & 17,474 & 64,813 & 3.62 & 3.52 & 4.44 \\
\hline 2 & 1389 & 3263 & 2984 & 36,783 & 50,697 & 4630 & 23,044 & 25,003 & 13,514 & 20,783 & 640 & 57,624 & 3.62 & 3.10 & 4.26 \\
\hline 3 & 1389 & 3387 & 3099 & 36,783 & 51,918 & 4152 & 23,044 & 23,746 & 71,208 & 20,783 & 640 & 670 & 3.62 & 3.08 & 3.62 \\
\hline 4 & 1389 & 3057 & 3643 & 36,783 & 5720 & 5141 & 23,044 & 14,643 & 13,956 & 20,783 & 56,116 & 56,322 & 3.62 & 4.26 & 4.24 \\
\hline 5 & 1389 & 980 & 1021 & 36,783 & 5325 & 3490 & 23,044 & 2128 & 2956 & 20,783 & 74,620 & 75,035 & 3.62 & 4.65 & 4.65 \\
\hline 6 & 1389 & 2138 & 8181 & 36,783 & 6636 & 4264 & 23,044 & 3848 & 4407 & 20,783 & 70,429 & 65,716 & 3.62 & 4.56 & 4.37 \\
\hline 7 & 1389 & 608 & 1348 & 36,783 & 220 & 195 & 23,044 & 803 & 647 & 20,783 & 81,421 & 80,333 & 3.62 & 4.79 & 4.74 \\
\hline 8 & 1389 & 1692 & 1652 & 36,783 & 39,382 & 3607 & 23,044 & 23,534 & 59,154 & 20,783 & 16,658 & 16,310 & 3.62 & 3.51 & 3.90 \\
\hline 9 & 1389 & 1548 & 2141 & 36,783 & 3955 & 3668 & 23,044 & 11,465 & 10,685 & 20,783 & 64,215 & 64,203 & 3.62 & 4.46 & 4.44 \\
\hline 10 & 1389 & 1861 & 2407 & 36,783 & 4203 & 4136 & 23,044 & 12,387 & 12,345 & 20,783 & 62,919 & 61,978 & 3.62 & 4.44 & 4.40 \\
\hline
\end{tabular}

between 2011 and 2030 for the sustainable development strategies, approximately 8 billion RMB was needed to achieve the goal of the policies. Although the cost is higher, it only represents $4.5 \%$ of Ordos's GDP in 2010.

\section{Discussion}

As one of the most important land surface ecosystems, desertified land and its dynamics are very complex due to the interaction of various factors at different temporal and spatial scales. In particular, the high spatial heterogeneity of human activities that can exhibit either positive or negative impacts creates great uncertainty in the reversal and expansion processes of desertification (Prince, 2002; Evans and Geerken, 2004). From this perspective, the SSD model can fulfill the requirements of desertification simulation and policy evaluation at different scales by quantifying the complicated relationship between desertification dynamics and driving forces (Matthies et al., 2007; Van Delden et al., 2007). In this study, an SSD model was developed by integrating six driving forces and selecting NPP as an intermediate variable to link and measure the driving forces and desertification dynamics. Submodels for social driving factors, such as pasturage and land use, were also designed to fully consider the perspective of policymaking for local government. Compared with other SD or SSD models for desertification simulation, the modeling framework is more comprehensible and can easily be expanded to different spatial scales. Furthermore, the area and the degree of desertified land can be modeled at the same time.

The selection of driving forces is very important for desertification simulation, as it determines the complexity, accuracy, and efficiency of the model. Considering the extent of the study region and previous studies (Xu et al., 2010), two natural factors and four social-economic factors were chosen to model desertification dynamics under a meso-perspective. This scale can reflect the most important processes of desertification and allows a relatively higher computing efficiency than finer scales, and the meso-scale has been adopted in previous studies of desertification simulation (Van Delden et al., 2007; Helldén, 2008; Rasmy et al., 2010). According to the validation results, the model developed in this study can achieve an acceptable accuracy. However, it does not mean the structure of this model is perfect, and there still have some limitations that will affect the ability of model prediction. For example, this model is relatively weaker to explain the impacts of national economic development policies, regional urbanization and agriculture production market on local farmer behaviors in land use and pasturage. Actually, it is an important mechanism that will directly affect desertification dynamic. As the research conducted by Van Delden et al. (2007), choices made by individual farmer according to crop profit were considered and modeled as an important factor of desertification, which could reflect the effect of market and macro-policy on desertification. So, in future study, more mechanisms among policy, farmer behaviors and desertification dynamics, such as the impact of ecological compensation policy, will be considered for improving the structure of this model (Reed, 2008; Van Delden et al., 2011).

In this study, due to a lack of statistical data (e.g., livestock number), some feedback processes among the desertification driving forces were modeled relatively coarser, which would also lead to the uncertainties in model results. For example, the only available statistics that could be used to simulate livestock numbers were birth rate, death rate, sell rate and slaughter rate, and it is very difficult to obtain a robust curve due to lack of considering the policy and market factors. This may have an impact on the simulation accuracy of livestock number and grass consumption. So, additional detailed statistical data, such as the data that can explain the relationship between sell rate and market demand, are needed in the future to decrease the errors and uncertainty of the model. Besides, the simulating method of some specific sub-models are also needed to be improved, such as soil water, population and the classification criteria of NPP for different desertification grades. For example, in the soil water sub-model, a simple statistic relationship was used to model the impact of NPP on soil texture, which could not accurately reflect the physical mechanism and process of soilvegetation interaction and their impact on soil water. In the submodel of population, the rate of urbanization was only treated as the result of economy development, and the resources and environment carrying capacity and its impact on urbanization were not considered. In the sub-model of desertification, the same classification criteria of NPP for desertification grade were used for the whole area of Ordos, and the differences between ecosystems at finer scales were not considered. In order to reduce the uncertainty induced by these limitations, great effort should be done in the future modeling. For example, a process-based model that can simulate the impact of vegetation on soil texture, land surface runoff and soil water content would be integrated in the sub-model of soil water; and the resources and environment carrying capacity would be introduced in the sub-model of population to determine regional urbanization rate and the spatial distribution of rural population. For desertification classification, different NPP classification criteria for desertification grades will be developed in the future, especially for simulations at larger scales.

Meanwhile, different parameters exhibited different sensitivities in the model. Generally, climate parameters had relatively higher sensitivity, especially rainfall, which agrees with reported characteristics of arid and semi-arid regions (Prince, 2002). The desertification control policy also had an obvious impact on vegetation rehabilitation, which is reflected in the higher $S$ values for banned grazing rate and planting grass in unused land. Meanwhile, 
the banned grazing rate was more sensitive, which could be used to explain why large scale implement of banned grazing policy in north China over past decades (Huang et al., 2013). Due to the complex mechanisms that link macroeconomic and social policies to vegetation dynamics, the change in population and economy did not result in a significant change of NPP. However, the sensitivity analysis conducted in this study could only reflect the influence of a single parameter, and a global sensitivity analysis should be designed and conducted in future (Salteli and Annoni, 2010), which would be used to optimize the model structure.

The desertification dynamics in Ordos from 2011 to 2030 under different scenarios were simulated in this study. Although these simulations could not precisely predict the real desertification status in Ordos, they illustrate some probable future desertification dynamics and can provide some inspiration for policy-makers. For example, the comparison of the baseline scenario and blank scenario indicated that the desertification prevention policies launched between 2000 and 2010 must be continued in the future; and if these policies are not continued, the desertification degree would reach 'high desertification' in 2015. As another example, the sustainable development strategy did not have the desired effect because of the rapid increase in pasturage pressure after 2025. Thus, the local government should completely implement banned grazing policy in Ordos after 2025, which could help maintain the benefits of desertification prevention. In terms of the desertification prevention cost, although the cost is high, it is affordable for the local government especially compared to the rapid increase of GDP. Thus, the local government should gradually increase the input for desertification control and enlarge the scale of ecologyprotecting projects. Meanwhile, raising the ecological compensation standard for the enterprises that harm the environment would also enlarge the cash pool for desertification control. For future analysis and policy support, Representative Concentration Pathways (RCPs) scenario data and more detailed social and economic development scenario data will be added to simulate desertification dynamics.

\section{Conclusion}

Desertification simulation is very important. It can be used to predict desertification dynamics in the future, and it can also be employed by policy-makers to evaluate and implement desertification control policies and projects. In this study, an SSD model was developed by incorporating spatial data into a traditional SD model. NPP was selected as a common indicator to measure the impacts and feedbacks of six driving forces and measure the different desertification grades. The application and validation in the city of Ordos, China illustrates that the model developed in this study is reliable and could achieve an acceptable level of accuracy. For the parameters of model, climate factors have relatively higher sensitivities, and the sensitivity of desertification control policy (e.g., banned grazing) is also higher than other social and economic parameters.

However, there still exist some uncertainties in the process of simulation; the model structure, simulating method of some specific sub-models and the integrating strategies are needed to be further improved, such as soil water. As an SSD model that integrated bio-physical and socio-economic processes of regional desertification, there still have a lot of efforts to do for enhancing the ability of policy-making support in future, especially for the dynamic policy themes. So, the policy target and decision demand are need to be accurately translated to scientific models, and these scientific models should have the ability to integrate the key biophysical and socio-economic processes of desertification, which would significantly reduce the uncertainties of model.
Modeled desertification in Ordos from 2011 to 2030 varies greatly under different scenarios. Although a more humid climate and sustainable development strategy would reduce both desertified land area and desertification degree before 2025, the rapid increase in pasturage pressure offset the benefits of desertification prevention in Ordos before 2025. The unsustainable development strategy and more arid climate accelerated the desertification expansion. Under the more arid climate condition, the sustainable development strategy significantly reduced desertification degree and achieved the same status in 2030 as the baseline scenario in 2028. Abolishment of desertification prevention policy caused the desertification degree of Ordos to reach a 'high desertification' level in 2015. Local government should persist in the present desertification prevention policy and initiate a policy that completely forbids grazing after 2025 to prevent desertification expansion. Meanwhile, the local government should also increase the financial support for desertification control.

\section{Acknowledgements}

This research was jointly supported by the National Natural Science Foundation of China (Project 71573245 and 71103170 ), and the National Key Technologies R\&D Program of China (2012BAC19B09).

\section{References}

Batty, M., Xie, Y., 1997. Possible urban automata. Environ. Plan. B 24, 175-192.

Batty, M., Xie, Y., Sun, Z., 1999. Modeling urban dynamics through GIS-based cellular automata. Comput. Environ. Urban Syst. 23, 1-29.

Ding, H.P., Chen, J.P., Wang, G.W., 2009. A model for desertification evolution employing GIS with Cellular Automata. Int. Conf. Comput. Model. Simul. IEEE 39, 324-327.

D'Odorico, P., Bhattachan, A., Davis, K.F., Ravi, S., Runyan, C.W., 2013. Global desertification: drivers and feedbacks. Adv. Water Resour. 51, 326-344.

Evans, J., Geerken, R., 2004. Discrimination between climate and human-induced dryland degradation. J. Arid. Environ. 57, 535-554.

Feng, J.M., Li, X.H., Zhang, J.L., 2010. Application of the Markov process model on the dynamic change of land desertification in the Gonghe basin in Qinghai Province. Chin. Agric. Sci. Bull. 26, 309-313.

Field, C.B., Randerson, J.T., Malmstrom, C.M., 1995. Global net primary production: combining ecology and remote sensing. Remote Sens. Environ. 51, 74-88.

Haberl, H., Erb, K.H., Krausmann, F., Gaube, V., Bondeau, A., Plutzar, C., Gingrich, S., Lucht, W., Fischer-Kowalski, M., 2007. Quantifying and mapping the human appropriation of net primary production in earth's terrestrial ecosystems. Proc. Nat. Acad. Sci. U. S. A. 104, 12942-12947.

Hahn, B.D., Richardson, F.D., Hoffman, M.T., Roberts, R., Todd, S.W., Carrick, P.J., 2005. A simulation model of long-term climate, livestock and vegetation interactions on communal rangelands in the semi-arid Succulent Karoo, Namaqualand, South Africa. Ecol. Model. 183, 211-230.

He, C.Y., Shi, P.J., Chen, J., Li, X.B., Pan, Y.Z., Li, J., Li, Y.C., Li, J.G., 2005. Developing land use scenario dynamics model by the integration of system dynamics model and cellular automata model. Sci. China Ser. D. 48, 1979-1989.

Helldén, U., 2008. A coupled human-environment model for desertification simulation and impact studies. Glob. Planet. Change 64, 158-168.

Holechek, J.L., Pieper, R.D., Herbel, C.H., 2001. Range Management Principles and Practices, fourth ed. Prentice Hall, New Jersey.

Huang, L., Xiao, T., Zhao, Z.P., Sun, C.Y., Liu, J.Y., Shao, Q.Q., Fan, J.W., Wang, J.B., 2013. Effects of grassland restoration programs on ecosystems in arid and semiarid China. J. Environ. Manag. 117, 268-275.

Ibanes, J., Valderrama, J.M., Puigdefábregas, J., 2008. Assessing desertification risk using system stability condition analysis. Ecol. Model. 213, 180-190.

Ibanez, J., Martinez, J., Schnabel, S., 2007. Desertification due to overgrazing in a dynamic commercial livestock-grass-soil system. Ecol. Model. 205, 277-288.

Li, Y.C., He, C.Y., 2008. Scenario simulation and forecast of land use/cover in northern China. Chin. Sci. Bull. 53, 1401-1412.

Liu, Y.S., Wang, J.Y., Deng, X.Z., 2008. Rocky land desertification and its driving forces in the karst area of rural Guangxi, southwest China. J. Mt. Sci. 5, 350-357. Matthies, M., Giupponi, C., Ostendorf, B., 2007. Environmental decision support systems: current issues, methods and tools. Environ. Model. Softw. 22, 123-127.

Mu, S.J., Zhou, S.X., Chen, Y.Z., Li, J.L., Ju, W.M., Odeh, I.O.A., 2013. Assessing the impact of restoration-induced land conversion and management alternatives on net primary productivity in Inner Mongolian grassland, China. Glob. Planet. Change 108, 29-41.

Neuwirth, C., Peck, A., Simonovic, S.P., 2015. Modeling structural change in spatial system dynamics: a Daisyworld example. Environ. Model. Softw. 65, 30-40. 
Peters, D.P.C., Havstad, K.M., 2006. Nonlinear dynamics in arid and semi-arid systems: interactions among drivers and processes across scales. J. Arid. Environ. 65, 196-206.

Piao, S.L., Fang, J.Y., He, J.S., Xiao, Y., 2004. Spatial distribution of grassland biomass in China. Acta Phytoecol. Sin. 28 (4), 491-498 (in Chinese).

Potter, C.S., Randerson, J.T., Field, C.B., Matson, P.A., Vitousek, P.M.V., Mooney, H.A. Steven, A.K., 1993. Terrestrial ecosystem production: a process model based on global satellite and surface data. Glob. Biogeochem. Cycle 7, 811-841.

Prince, S.D 2002 Spatial and temporal scales for detection of desertification. In: Reynolds, J.F., Stafford Smith, D.M. (Eds.), Global Desertification: Do Humans Cause Deserts? Dahlem University Press, Berlin, Germany.

Puigdefábregas, J., 1995. Desertification: stress beyond resilience, exploring a unifying process structure. Ambio 24, 311-313.

Puigdefábregas, J., 1998. Ecological impacts of global change on drylands and their implications on desertification. Land Degrad. Dev. 9, 393-406.

Rasmy, M., Gad, A., Abdelsalam, H., Siwailam, M., 2010. A dynamic simulation model of desertification in Egypt. Egypt. J. Remote Sens. Space Sci. 13, 101-111.

Reed, M.S., 2008. Stakeholder participation for environment management: a literature review. Biol. Conserv. 141, 2417-2431.

Salteli, A., Annoni, P., 2010. How to avoid a perfunctory sensitivity analysis. Environ. Model. Softw. 25 (12), 1508-1517.

Saxton, K.E., Rawls, W.J., Romberger, J.S., Papendick, R.L., 1986. Estimating generalized soil-water characteristics from texture. Soil Sci. Soc. Amer. J. 50 (4), 1031-1036.

Song, N.P., Zhang, F.R., Li, B.G., 2005. Impacts of household fuel structure on land desertification in Eijin Horo banner. Resour. Sci. 27 (3), 86-91 (in Chinese).

Tao, F.L., Yokozawa, M., Zhang, Z., Xu, Y.L., Hayashi, Y., 2005. Remote sensing of crop production in China by production efficiency models: models comparisons, estimate and uncertainties. Ecol. Model. 183, 385-396.

United Nations Convention to Combat Desertification, 1994. United Nations Convention to Combat Desertification in Countries Experiencing Serious Drought and/or Desertification, Particularly in Africa. A/AC, 241/27, Paris.

Van Delden, H., Luja, P., Engelen, G., 2007. Integration of multi-scale dynamic spatial models of socio-economic and physical processes for river basin management. Environ. Model. Softw. 22, 223-238.

Van Delden, H., Kirkby, M.J., Hahn, B.M., 2009. Towards a modelling framework for integrated assessment in arid and semi-arid regions. In: Anderssen, B., et al.
(Eds.), 18th IMACS World Congress-MODSIM09 International Congress on Modelling and Simulation, Cairns, Australia. ISBN 978-0-9758400-7-8.

Van Delden, H., Seppelt, R., White, R., Jakeman, A.J., 2011. A methodology for the design and development of integrated models for policy support. Environ. Model. Softw. 26, 266-279.

Veron, S.R., Paruelo, J.M., Oesterheld, M., 2006. Assessing desertification. J. Arid. Environ. 66, 751-763.

Wang, T., Wu, W., Chen, G.T., Xue, X., Sun, Q.W., 2004. Study of spatial distribution of sandy desertification in north China in recent 10 years. Sci. China Ser. D. 47 (z1), $78-88$.

Wang, T., Song, X., Yan, C.Z., Li, S., Xie, J.L., 2011. Remote sensing analysis on aeolian desertification trends in northern China during 1975-2010. J. Desert Res. 31 (6), 1351-1356 (in Chinese).

Wang, F., Pan, X.B., Wang, D.F., Shen, C.Y., Lu, Q., 2013. Combating desertification in China: past, present and future. Land Use Policy 31, 311-313.

Wang, T., 2014. Aeolian desertification and its control in Northern China. Int. Soil Water Conserv. Res. 2 (4), 34-41.

Xu, D.Y., Kang, X.W., Qiu, D.S., Zhuang, D.F., Pan, J.J., 2009. Quantitative assessmen of desertification using Landsat data on a regional scale - a case study in the Ordos Plateau, China. Sensors 9, 1738-1753.

Xu, D.Y., Kang, X.W., Zhuang, D.F., Pan, J.J., 2010. Multi-scale quantitative assessment of the relative roles of climate change and human activity in desertification-A case study of the Ordos Plateau, China. J. Arid. Environ. 74, 498-507.

Xu, D.Y., Li, C.L., Song, X., Ren, H.Y., 2014. The dynamics of desertification in the farming-pastoral region of North China over the past 10 years and their relationship to climate change and human activity. CATENA 123, 11-22.

Yin, Y.H., Wu, S.H., Dai, E.F., 2010. Determining factors in potential evapotranspiration changes over China in the period 1971-2008. Chin. Sci. Bull. 55 (29) 3329-3337.

Zhang, H., Shen, W.S., Wang, Y.S., Zou, C.X., 2005. Study on grassland grazing capacity in the Heihe River basin. J. Nat. Resour. 20 (4), 514-521.

Zhang, G.L., Dong, J.W., Xiao, X.M., Hu, Z.M., Sheldon, S., 2012. Effectiveness of ecological restoration projects in Horqin Sandy Land, China based on SPOT-VGT NDVI data. Ecol. Eng. 38 (1), 20-29.

Zhang, B., 2008. A study of GIS-SD based temporal-spatial modeling of water quality in water pollution accidents. In: Paper Presented at the ISPRS Congress, Beijing. 